\title{
Teachers' perspectives about distance education for refugee students amid the COVID-19 pandemic in Greece: Challenges and Implications
}

\author{
Anastasia Gkaintartzi \\ Department of Language and Intercultural Studies \\ University of Thessaly, Greece \\ E-mail: againtartzi@uth.gr
}

Received: July 13, 2021 Accepted: Sep.26, $2021 \quad$ Published: November1, 2021

doi:10.5296/jse.v11i4.19003 URL: https://doi.org/10.5296/jse.v11i4.19003

\begin{abstract}
This article presents a small scale qualitative study which aims to investigate the teachers' perspectives, practices and experiences regarding distance teaching and learning among refugee students in Greece during the first wave of the COVID-19 pandemic. Through the teachers' voices, we attempt to initially map and frame the context of distance education for refugee students, as it was implemented during the first lockdown (March-May 2020) and understand the experiences, challenges and changes involved for both refugee students and teachers. The study was conducted through open-ended online questionmaires, which were completed by 27 participant teachers, teaching students with a refugee/migrant background in their classes and implementing distance teaching during the first COVID-19 school closure. The findings provide insights into the ways teachers and students responded to and experienced distance education as well as the challenges and possibilities involved. Implications are drawn for supporting vulnerable groups with language teaching/learning in crisis.
\end{abstract}

Keywords: distance education, COVID-19, refugee students, teachers' perspectives, Greece 


\section{Introduction}

The Covid-19 pandemic has affected the lives of millions people all over the world. The pandemic crisis has had a disproportionate impact on immigrant and refugees since according to OECD (2020), it has negatively affected refugees and their children in terms of health, jobs, education, language training, other integration measures and public opinion. Furthermore, the COVID-19 outbreak has also led to a major education crisis forcing school closures and distance learning measures, which have also further disempowered children of immigrants and refugees $(\mathrm{OECD}, 2020)$. Governments globally were very quick to react to mitigate the effects of the pandemic crisis through the suspension of face to face education and the launching of distance learning without, however, always taking into account many important factors and preconditions for the success of these policies, such as technical issues, teachers' readiness, access of all students etc (Kollender \& Nimer, 2020).

In Greece, during the first wave of the pandemic, the Government announced, on 10th March 2020, the closure of all educational structures and put into operation distance teaching and learning in all schools in the country. Distance learning was structured around three axes: 1) synchronous teaching 2) asynchronous and 3) educational television. For the inclusion of all students in the process, it was decided to provide free access from mobile networks to digital platforms for distance education. Greece progressively reopened educational institutions to students from 11th May 2020. Apart from this initial education policy response to the COVID-19 pandemic, the schools were suspended again, during the second wave of the pandemic, on 13th November 2020 and distance education was put into operation in all schools in the country until February 2021. Refugee students were disproportionately affected by these urgent educational responses in Greece since camps were officially locked down since March 2020 and the children were further restricted in many different terms. This small scale qualitative study attempts to investigate the teachers' perspectives, practices and experiences regarding distance learning and learning among refugee students in Greece during the first wave of COVID-19 pandemic. The findings can provide insights into the ways distance education may contribute to the refugee students' empowerment or disempowerment, the challenges but also possibilities involved and implications for supporting vulnerable groups with language teaching/learning in crisis.

\subsection{COVID-19 and its effect on the education of immigrants and refugees}

The pandemic crisis has definitely had a global effect but the world's 71 million refugees and forcibly displaced persons are among the most heavily impacted (UNHCR, 2020). Among the factors that are reported to be affecting the education of children of immigrants are the unequal access to distance learning since the children tend to be less likely to have access to a computer and an internet connection or an appropriate place for study (UNESCO, 2020a, 2020b). Also, immigrant/refugee parents tend to have fewer resources to help them with their homework while a considerable number of children and families may not speak the host country language (OECD, 2020). A study on the impact of COVID-19 on refugee students in the German and Turkish educational systems (Kollender \& Nimer, 2020) has shown that the lack of access to technological devices and an internet connection emerged as an important 
challenge towards the access of refugee children to online education. Language barriers were also evident in both contexts to be hindering communication and understanding in digital learning while lack of communication with parents was an additional challenge (Kollender \& Nimer, 2020).

On the whole, apart from the economic and technological resources needed to engage in distance education, a degree of language competence in the language of instruction is also required in order to understand and participate in the leaning process. Also, parents are required to support home learning to different degrees and in various ways, which entails many barriers for immigrant/refugee families such as the linguistic and the lack of communication as well as lack of time and other resources, according also to international data (Edmonds \& Flahault, 2021). Furthermore, the economic impacts of COVID-19 are also expected to have a disproportionate effect on refugee families which in turn affects their education, increasing their vulnerability. Globally, COVID-19 has presented a significant threat to refugee education and refugee students are particularly disempowered since due to ongoing exclusion in many national education systems, they may not have been included in the COVID-19 response (Save the Children, 2020).

\subsection{The Greek context of refugee education before and after COVID-19 at a snapshot}

Regarding refugee education in the Greek context, the Greek government and the Ministry of Education since 2016 took tangible measures for the official provision of education and inclusion of refugee children, following the confinement of thousands of refugees in the country after the closure of the "Balkan route" (Refugee Support Aegean, 2021). In specific, since the Balkan Route closed and only those deemed eligible for relocation and family reunification programmes were allowed to move to other European countries, about 62,000 refugees (27,000 children) were trapped in Greece (Simopoulos \& Magos, 2021; UNICEF, Refugee and Migrant Children in Greece, 2019, 2020).

The framework of educational measures addressing refugee children, which was put in operation since 2016, included:

a) the establishment of Reception Facilities for Refugee Education (RFRE) in certain public schools, during afternoon hours, geared to refugee and migrant children (aged 6-15 years) residing in accommodation centers (Reception and Identification Centres (RIC) and mainland camps);

b) the establishment of kindergartens in the accommodation centers;

c) setting up Reception Classes within Educational Priority Zones addressing children who live in urban areas in order to support them with Greek language learning. In these zones, students participate in the mainstream curriculum with Greek peers in morning classes and take 3 hours of preparatory classes (RC) for language support in Greek (Refugee Support Aegean, 2021);

d) the framework also included the appointment of Refugee Education Coordinators to act as facilitators of the whole process, of the enrollment and attendance of students (Manoli et al., 
2021).

Additionally, educational material has been provided on the platform of the Institute of Educational Policy, along with curricula, guidelines and NGOs' educational material (Gkaintartzi et al., 2021). Non-formal education has been also provided by several NGOs and organizations, which are shown to be highly active by offering courses and through other initiatives, projects and actions (Zambeta et al., 2019). Despite these measures and the significance progress in the students' enrollment rates in RFREs (from 2016 to 2019) an important, still, number of refugee students are excluded from public education, especially children who have been restricted into Reception and Identification Centers in the Eastern Aegean islands, as well as a large number of adolescents (Simopoulos \& Magos, 2021). Significant deficiencies concerning the quality of education provided to refugee children, mainly in RFREs, but also in the formal curriculum have been documented in several reports and studies (Stergiou\& Simopoulos, 2019).

After the outbreak of the COVID-19 pandemic, in March 2020, the Greek government, in the context of the whole country's lockdown, imposed movement restrictions on the residents of RIC and mainland camps, according to which only certain people as representatives were allowed to move out and in the facilities within specific hours for their needs (Refugee Support Aegean, 2021). These measures were successively prolonged for refugees in camps. The closure of schools and the shift to online teaching/learning, which followed on the 10th March, during the first wave of the pandemic, required from all students, including refugees, to engage in distance learning. The Ministry of Education launched the use of digital tools, such as Webex (https://www.webex.com/), a Cisco software, to be usedl as a synchronous platform for online lessons and e-me (https://e-me.edu.gr) or e-class (https://eclass.sch.gr/) platforms for asynchronous distance education. It also set up a website (https://mathainoumestospiti.gov.gr/) to provide distance learning tools, ideas and information for education at all levels.

Several challenges are reported regarding all students, which include the lack of internet connection and digital equipment, teachers' lack of online teaching experience and readiness to teach digitally as well as the difficulties met be parents with limited digital competence and other resources to assist their students (Eurydice, 2021). The Greek Government tried to address several of these challenges by establishing a helpdesk, organizing online training seminars and webinars for teachers and donating equipment at a later stage (tablets and laptops) to those in need. However, these challenges had a significant and disproportionate impact on refugee students in particular. Most refugee children as well as other children from disadvantaged backgrounds, were confronted with significant barriers in participating in remote and digital learning. Challenges such as the dire conditions in RICS and mainland camps including lack of internet access, as well as lack of stable electricity are reported along with difficulties in maintaining a stable internet connection (Refugee Support Aegean, 2021). Moreover, lack of technical equipment was a further barrier since many families had to share only one mobile phone while there were a lot of bureaucratic and other obstacles in the actual implementation of the government financial support for equipment purchase to those in need (Refugee Support Aegean, 2021). The lack of language skills to facilitate understanding (e.g. 
instructions and links in Greek only) among children and their families but also the lack of other technical skills required to participate effectively in distance learning was also a significant barrier to the education of these children. During the first and the second wave of the COVID-19 pandemic, there were many reactions and concerns expressed in the public sphere about the exclusion of refugee students from distance education, which operated as a national educational policy and response. This study attempts to investigate and map initially, through the teachers' perspectives, the teaching/learning experiences with distance education for refugee students during the first wave of the pandemic in order to fill in the gap in research in Greece about this issue during the pandemic, draw some initial implications for further research and contribute to our documented knowledge base about it.

\section{Method}

The aim of the small-scale qualitative research is to investigate the teachers' perspectives, practices and experiences with distance teaching/ learning amid the first COVID-19 pandemic wave in the context of education of refugee students in Greece. Through the teachers' voices, we attempt to map initially and understand the experiences, challenges and possibilities, for both refugees students and teachers, related to distance learning/teaching, as it was implemented in the first wave of the pandemic. This initial mapping of teachers' perspectives is followed by follow-up interviews with some of the participant teachers, after the second wave of COVID-19 in Greece, that is one year after, in order to study and understand how these experiences may have developed in time and changed.

In specific, the research questions were :

- What are the challenges and the barriers that refugee students and teachers faced in the process of distance teaching/learning?

- What are the practices employed by teachers and Coordinators of Refugee Education in distance education for refugee students and how did they respond to the challenges?

- What are their perspectives about the way distance education addressed refugee students, their inclusion and the learning opportunities offered?

The study, in its first stage, was conducted through open-ended online questionnaires, which were delivered to teachers teaching refugee/migrant students, who were also involved in distance teaching/learning during the first wave of the pandemic (March 2020) as well as to Refugee Education Coordinators. It was implemented throughout May and June 2020. Follow -up interviews with some of the teachers-participants are also conducted in the second stage of the research (Autumn 2021), focusing on the teachers' reflections, transformations and the potential long-term impact of distance-learning on their practices and contexts. This paper presents the findings from the first stage of the research, which inclluded the teachers' open-ended on-line questionnaires during the first lockdown in March 2020.

\subsection{Participants, research tool and data analysis method}

The participants were twenty-seven teachers working in formal and non-formal educational contexts with students of a refugee and migrant background. Convenience and purposive 
sampling were used to select the participants. They were selected based on the criterion of teaching students with a refugee/migrant background in their classes at the time of the research process. The participants were mostly primary school teachers and Greek language teachers including also teachers of foreign languages and of preschool education. Their detailed profiles are presented below in the Findings as they were derived from the research data. The teachers' questionnaires were delivered and completed electronically. The questionnaire included 24 open-ended questions regarding their profile, their practices during online teaching/learning, the challenges and barriers that emerged as well as the inclusion and participation on the part of their students. Open- ended questions were included and thus the approach is considered to be qualitative. The data was analyzed using qualitative Thematic Analysis (Braun \&Clarke, 2006).

More specifically the themes that emerged from the data analysis were the following:

1. Tools and Materials

2. Changes and challenges

3. Benefits and opportunities

4. Access and In(ex)clusion

\section{Findings}

\subsection{Teachers' profiles}

Starting from the profiles of the teachers, the majority of them were women (26/27). A considerable number of them $(40.6 \%)$ had a teaching experience of $1-5$ years and the rest ranged from 6-10 years (11\%), 11-15 years (18.5\%) and 15-20 (18.5\%). Also, almost half of them held a Master's degree. Most of the teachers (60\%) worked in formal educational contexts, that is state schools (primary, secondary and preschool education) while the rest in non-formal contexts, i.e. NGOs. Half of the teachers in formal contexts taught in Reception Facilities for Refugee Education (RFREs) and Reception Classes while the others worked in mainstream state school classes, which also included refugee/migrant background students. The teachers in non-formal contexts worked for NGOs and accommodation centers, providing also education to refugees and migrants. The majority of the participant teachers as a whole worked with children (pre-school and primary school levels) and teenagers (12-16 years old) while a very small number of them (11\%) taught adults.

Regarding their prior experience or training on distance and online teaching, 9/27 (33\%) answered that they did not have any kind of prior knowledge or experience while a considerable percentage of them (67\%) replied that they had a prior experience in distance teaching/learning. This prior experience was mostly acquired, however, as students and trainees in distance education programmes while in fact only a very small number of them had actually taught online before. Regarding the question about whether they did use distance education to teach their students (throughout the first lockdown in March 2020) the vast majority gave positive answers whereas three of them replied negatively. The reasons they 
gave for not using it was the lack of technical equipment and support, the students' lack of access due to having no internet connection or equipment.

\subsection{Tools and Material}

Regarding the methods and tools with which distance learning was applied, almost all of them used both synchronous and asynchronous methods. In specific, they taught and communicated with their students in real time, using Webex (in formal educational contexts) and skype and zoom (in non-formal contexts). They communicated with their students via e-mails, viber, facebook while asynchronous tools were used to upload material and activities, mostly using e-class, e-me (in formal contexts), Edmodo, and a FB group/page (in non-formal) while there was a case in an NGO, where a website of their own was created for their needs. As expected, the teachers in formal contexts followed the directions given by the Ministry and used the tools provided to them (Webex and e-class/e-me), while in non-formal contexts the teachers used a variety of tools, both synchronous and asynchronous. A higher degree of flexibility concerning the digital tools is evident among teachers in non-formal contexts while teachers in formal contexts, apart from the tools directed from the Ministry, used e-mails too, to communicate with their students.

Concerning the teaching material that they used, a variety of materials is reported by the majority of the teachers such as videos (youtube), online activities, games, puzzles, songs, coursebooks/e-books, digital educational platforms (e.g. educaplay, learningapps), Photodentro (the Greek national aggregator of educational content) and material they designed on their own, using digital tools (e.g. prezi, ppt, quizlet, wordwall, h5p etc). As it is seen from their replies, teachers in both contexts used a variety of materials to adapt to the new teaching/learning environment and showed willingness and creativity in selecting and employing different types of materials as well as creating material on their own.

\subsection{Changes and Challenges}

Accordingly, the main alteration that most teachers (65\%) were led to make regarding their teaching practices concerned the teaching material that they had to use, which according to their replies needed to be more explanatory, digital and multimodal, simple and easy to understand, supplemented with videos, ppt presentations, online activities with immediate feedback. Having more teaching time available and decreasing the amount of syllabus to be taught were also reported as changes and adjustments they had to make throughout online distance learning. Interestingly, what emerges from their responses concerning their practices, is an increased teacher agency and autonomy via distance education in designing/adapting educational material, dealing with the teaching time and the syllabus differently, more flexibly and engaging with multimodality in their teaching. A small percentage of them (13\%) mentioned the factor of communication and contact with their children which had to change and thus their lessons lacked the immediacy of physical and face-to -face communication. Below follow extracts from their replies: 


\section{Ml Macrothink}

Journal of Studies in Education

ISSN 2162-6952

2021, Vol. 11, No. 4

"I tried my material to be interesting, not to tire the children out and somehow experiential...for the refugee children I differentiated the material so as to be more comprehensible."

"The lack of personal contact with my students is a major change."

" 1.The daily pre-designed PowerPoint presentation in contrast to face-to-face teaching, in which the lesson plan came out partly through discussions with the students. 2.online exercises with automatic correction and feedback. 3. Daily detailed feedback to all children who uploaded exercises in asynchronous education"

As it is seen, the transition to online teaching/learning involved also a shift in several teaching practices and it could have led teachers to take on a more active, autonomous and professionally aware role concerning the educational material and tools compared to their prior educational context. This needs to be further investigated and attested through the follow-up interviews of our study one year after, so as to examine whether this change could have led to transformations in their practices. They did show a degree of self efficacy in adapting their teaching regarding the material, differentiation of material and activities as well as their feedback (König et al., 2020). Maintaining, however, communication with their students and parents in some cases, seems to be a significant challenge. This change in their contact and communication, which had to be organized completely differently, was a major challenge since it seems that teachers and students, especially in contexts of teaching/learning Greek as a second/additional language, rely much on their face-to-face contact and interaction in class for communication and language learning/teaching.

Concerning the challenges that emerged, the majority of teachers $(60 \%)$ referred to technical issues which involve the lack of access to internet, lack of equipment, instability of internet connection and technical problems (e.g. overloaded connection). A smaller number of them $(28 \%)$ reported the lack of digital skills and competence on the part of the students and in very fewer cases of parents too whereas only 2 teachers $(8 \%)$ referred to lack of digital skills on the part of the teachers too. Language and communication issues were also reported by 5 teachers $(20 \%)$, including difficulties in understanding instructions, lack of face-to-face interaction among the students themselves and with the teacher, as well as the teachers' uncertainty about the students' actual participation and response to the activities and the whole process. Other challenges including irregular school attendance, communication with parents and methodological issues such as lack of use of group activities, experiential methods and individualized teaching were also mentioned, as seen in their own words below.

"Initially we had to discuss many procedural issues, such as how to enter the platform and how to use it. Some students did not manage to participate at all, because they are not familiar with new technologies. There were many technical problems, while the course was interrupted several times due to poor internet connection. The possibility of direct error feedback was reduced. Also, the students did not register at all at the asynchronous (platform) and they did not have access to the platform of the Ministry of Education. Because in this class there are many levels of knowledge of Greek and English, which we use more as a link language, I apply individualized teaching. In distance teaching, I did not have the possibility 
for individualized teaching."

"What the student gains from it (distance education). The choice of asynchronous (mode of) education using a website did not leave any room, any 'window' for interaction with the students, nor did we know if the educational material found any response, if there was anyone who was involved with it."

"Personally, I was puzzled about what we were required to do, as it did not seem to have much of an impact on the target group we were addressing. Also, some students even if they had access to the FB group / page, they did not understand what to do, because they were not familiar with this type of exercises and education."

"Social divisions were further emphasized.It was more difficult to employ individualised teaching."

A sense of uncertainty is evident from the teachers' responses, who experienced these changes while feeling unable to address their students' needs adequately, to receive and understand their students' response to and actual engagement with the whole teaching/learning process. A feeling of loneliness could also be inferred from their words. The 'social divisions' explicitly referred in the above quotation, which imply the refugee students' further disempowerment and exclusion, is a political voice, which analyzed deeper the changes involved in distance education and pointed out the issue of equity and inclusion.

When asked about the challenges that their students, in particular, faced, the majority of the teachers (76\%) reported technical issues such as lack of access to internet and lack of equipment. A smaller number of teachers (24\%) referred to the students' lack of digital competence and skills to be able to use the tools required and participate adequately in the teaching/learning process while $20 \%$ of them reported language difficulties in understanding and communicating. Lack of parents' interest to assist their children and motivation on the part of the children themselves was only reported by two teachers.

"Many students did not understand what they had to do.They may have needed more the social aspect of education rather than the cognitive one.They did not have, perhaps, increased motivation to see and try to see what was all this that we uploaded.I think what they needed more was to communicate with the teachers themselves."

The students may have felt alone too during distance teaching/learning, according to the teacher, since they could not receive though this type of education the support and sense of inclusion they needed; the personal relationship and communication with their teachers seems to have been lost. The practices that were employed by the teachers to cope with the challenges mostly involved the facilitation of communication and understanding by organizing supplementary online meetings, providing detailed technical instructions, notes and videos, using social media and other tools to communicate (such as messenger, what's up, Twiddla and Google Docs), reaching and involving parents as well as working with other teachers and coordinators. It seems that the teachers tried hard to overcome the communication and linguistic barriers involved in the distance education of refugee students. However, they reported their inability to cope with and solve the technical issues that emerged. 
"The instructions I sent to the students included screenshots with steps to follow about issues such as how to sign up for the National School Network, to log in to the e-me platform and use it, to understand how to connect to Webex and even how to attach a file and send by email.We made sure that the school's website has the option to choose another language so that parents and students can understand the announcements.The lack of equipment, however, could not be solved."

"1. Daily feedback, 2.Personal messages, 3.Using the "wall" in the e-class as a means of interaction, 4. Switching on the cameras"

What seems to emerge from the teachers' replies is that they devoted personal time and sought ways to communicate, explain, support and reach out for the students, some of which included also trying to involve parents more actively and working together with other colleagues. Their sense of disappointment, however, regarding the technical barriers which they were unable to overcome, is evident in most of their replies.

\subsection{Benefits and Opportunities}

The majority of the teachers (62\%) referred to benefits of distance learning regarding pedagogical and methodological issues. In specific, they reported the advantages of using ICT in language teaching, the variability offered in the teaching process, the flexibility of student study but also the flexibility of work provided to teachers, saving teaching time, offering convenience and multimodality in teaching. Also, some pedagogical benefits included the increased interest and motivation of students and the increased participation of weaker or less confident students compared to the school classroom.

"The dynamics of technology. The entertaining 'window' to the world it offers. The ability to study in the conditions you choose, in the security of your home (when of course there is an internet connection). The ability to use videos with realistic dialogues although some may not be of good quality. The short duration and the concentrated meaning[...].The student-centered approach."

"We could use a variety of digital tools in relation to conventional teaching because I do not have a computer in the classroom at school. This would benefit students if they had access to the platforms."

"Students answer without being afraid of the criticism of their classmates".

A very small number of teachers ( $8 \%$ ) reported the development of digital skills and literacy on the part of the students and the teachers too, as an important asset gained from distance teaching/learning. There was a considerable percentage of teachers $(25 \%)$, however, who found absolutely no benefits and advantages to be gained from online teaching/learning, reporting that they did not find any positive aspects, as shown in their replies below.

"In our case there were no advantages."

"No benefit, you just get a little more creative in the material you prepare." 
" I believe that online teaching is a solution of necessity only in the case when conventional teaching is impossible. I do not think there are any benefits for these students unless it is blended with the conventional one."

As seen, their answers can be placed on a continuum since there were teachers who could not find any benefits and advantages that distance education had to offer in their cases, as it was implemented, especially regarding their students. These are the cases in which the technical barriers had impacted so negatively the whole process and their studlents' participation, leading to almost no positive outcomes, including also teachers who believe that refugee students cannot learn effectively without being involved in face-to- face teaching.

\subsection{Access and In(ex)clusion}

According to the participant teachers' responses to the question of whether their students had equal access and opportunities of learning through distance education during the first wave of the pandemic, the vast majority answered negatively $(80 \%)$ whereas only very few teachers $(20 \%)$ responded positively. All of them justified their answers by referring to the lack of resources, the dire living conditions as well as lack of digital skills and competence. Their prior disadvantaged social position, the insufficient infrastructures and facilities provided from the school, their parents' lack of support and involvement at home and lack of face- to -face interaction were also included in their answers. For the majority of teachers, the technical barriers had further socio-political dimensions, hindering the students' already unequal access to learning and thus contributing to their further disempowerment and invisibility.

"Of course, they did not have equal access and learning opportunities.Apart from their socio-economic status, the low standard of living and the low to non-existent (language) knowledge of their parents, these students attend a school that provides them with only the basics, which do not include digital literacy due to lack of infrastructure."

"The Greeks yes, the refugees not, because they did not have the means and distance education restricted communication and interaction with classmates."

"Because: 1. Some did not have the equipment and an internet connection, 2. Some participated only from mobile phones 3. Some did not know how to use the tools and platforms, 4. Some did not have help from their home (parents) to overcome these practical problems, 5. Some children have not developed mechanisms of learning and self-regulation of their learning and need (more) the physical presence of the teacher, to motivate and engage them."

The few teachers (20\%), who responded positively, came from non-formal educational contexts and formal mainstream classes (i.e. not reception classes or RFREs).

"Yes.We had all access to internet and the time of the meetings was decided by mutual consent."

"The accommodation shelters provided many opportunities and many were open to help with any proposal for the education of the children." 
Their answers may be affected by the specific chronotope of teaching/learning (Blommaert, 2015) (e.g. non/formal educational contexts) and the ways they managed to handle the whole process as well as the support, the means and the technological resources they had available for teaching/learning from their school/organization.

\section{Discussion}

The disruption of education with the closure of schools during the pandemic crisis and the shift to distance learning has had a significant impact on the education of refugee students as well as on the teachers' practices, as shown from the data analysis. According to the teachers' perspectives, the challenges that their students encountered mostly involved the technological barriers which were found to exacerbate the exclusion of refugees from education and thus contributed to their further disempowerment and invisibility. This is consistent with international studies and reports too, which document the lack of access of refugees to online education (UNESCO, 2020b). Even since 2016, according to UNHCR (21016) refugees were 50 percent less likely than the general population to have access to devices with internet capability. By that very fact, a majority of refugee students would be excluded from any form of distance education in times of the pandemic. Thus, lack of access to technological devices and an internet connection emerged as a significant challenge, along with the dire conditions that the students already lived in (e.g. shelters, camps or flats) making homeschooling inappropriate and non-feasible. These special needs of the children and their families have to be taken into account as well as the barriers that (refugee/immigrant) parents are confronted with in order to be able to support their children at home and engage in their education. The, already preexisting, educational challenges for refugees, seem to have been intensified though distance teaching/learning (Kollender \&Nimer, 2020). Language barriers, the lack of face- to -face communication and interaction with the teachers and among the students themselves, the absence of translators emerged as challenges too, which further led to their disengagement and decreased motivation. Lack of digital skills and competence on the part of the learners and the teachers as well impacted the whole process.

Turning to the opportunities which emerged, according to the teachers, most of them seem to involve the teachers' development of competence in using and designing a variety of different teaching materials and tools and generally in adapting and shifting their teaching to digital environments. According to other studies (König et al., 2020), digital teacher competence is considered very important in adapting to online teaching during COVID-19 pandemic and school closures while searching for and selecting online teaching materials is found to be a significant aspect of this competence. Some methodological and pedagogical benefits were also reported, showing that online platforms and digital tools can facilitate and improve student participation compared to traditional classrooms, in some cases and under certain conditions, i.e. if issues of access to all are already solved. The long-term impact of the COVID-19 pandemic on education and, in specific, on refugee education needs to be further investigated since it will possibly have longer-lasting effects. Although distance learning approaches can and have proved to be instrumental in including some refugee and immigrant students, who are traditionally excluded from education, the reality globally in most cases shows limited access to digital technology, unreliable internet and electricity and other 
linguistic/cultural barriers (Save the Children, 2020). According to UNHCR $(2016,2021)$, the disruption in education caused by COVID -19 for refugee learners, who had already been confronted with barriers to access education, is highly more severe, posing serious and long-term threats to their inclusion and wellbeing. This impact needs to be further examined in the long term after the opening of schools, since it will continue to affect students, especially the most vulnerable groups. Through the perspectives and the experiences of the teachers of the study we can also understand their struggle, their feelings of uncertainty and sense of inability to support their learners adequately, the changes along with the demands and responsibilities. Thus, teachers need partnerships, support and training in order to be able to implement such educational responses in times of crisis.

\section{Conclusion}

This study attempted an initial mapping and framing of the context of distance education for refugee students during the first wave of the pandemic in Greece, in order to provide some insights and draw some implications for further research and educational practice. As COVID-19 is an evolving, unprecedented situation, our aim is to highlight the importance of considering the teaching/learning experiences that emerged in the context of distance education for refugees during the COVID-19 pandemic. Further research is needed to investigate the long-term impact of this educational response, after the second wave of the pandemic in Greece too, that is one year after, in Autumn 2021. Our follow-up interviews with the teachers will provide data about how processes, practices and perspectives may have been transformed due to this educational crisis and what might be the longer-lasting effects on teachers', students' and families' educational practices. The students' and parents' voices need also to be investigated and heard in order to be able to fully understand their educational experiences and draw concrete implications for their education. Large-scale quantitative studies are also needed such as the ones in progress by Maaoui, Tsagari and colleagues (Maaoui et al., 2021) examining the way school teachers and university/college teachers have been responding to assessment challenges in the COVID-19 pandemic as well as investigating language educators' practices working online during the COVID-19 pandemic (Tsagari et al., 2021).

For all stakeholders, professionals and teachers our findings add to the awareness of the need to ensure that distance education approaches have to be inclusive, equitable and contextualized. First most, the state and its educational system needs to cater for adequate resources and educational funding (allocation and distribution) so as to ensure access to education for all and support the inclusion of disadvantaged groups to education. Apart from ensuring availability of technological resources and equipment as well as access to internet connection for all, continuous learning opportunities so as to be able to use digital tools should be provided to both students, parents and teachers. We could also conclude from our findings that teachers can and do employ practiced language policies (Young, 2014), at a micro-context, both in non-formal but also in formal educational settings, including bottom up policies, showing flexibility and creativity with the teaching material and supporting learners in various ways in order to empower refugee students and facilitate their inclusiveness. These teachers, who are the key actors in implementing distance education 
approaches need support, partnerships and training in order to be able to adapt their practices to new environments, make safe transitions from one space to another and act as agents more actively in decision-making, policy-making and teaching. We need to reflect and learn from the challenges and the valuable 'lessons' offered by the COVID-19 pandemic, strengthen our evidence-based knowledge and contribute to making educational systems more resilient, inclusive and equitable so as to fulfill the right to quality education for all.

\section{References}

Blommaert, J. (2015). Chronotopes, Scales, and Complexity in the Study of Language in Society. Annual Review of Anthropology, 44(1), 105-116.https://doi.org/10.1146/annurev-anthro-102214-014035

Braun, V., \& Clarke, V. (2006). Using thematic analysis in psychology. Qualitative Research in Psychology, 3(2), 77-101. https://doi.org/10.1191/1478088706qp063oa

Gkaintartzi A., Mouti A., Papapostolou A., \& Sarantopoulou P. (2021). Language education for refugees and migrants in the Greek context: the stories of language teachers within formal and non-formal educational settings. In Chatzidaki, A., \& Tsokalidou, R. (Eds.), Challenges and Initiatives in Refugee Education: the case of Greece, (pp. 57-80), Cambridge Scholars Publishing.

Edmonds, J., \& Flahault, A. (2021). Refugees in Canada during the First Wave of the COVID-19 Pandemic. International Journal of Environmental Research and Public Health, 18(3), 1-16. 947. https://doi.org/10.3390/ijerph18030947

Eurydice (2021). Greece: Support to primary and secondary school teachers put in place during the pandemic https://eacea.ec.europa.eu/national-policies/eurydice/content/greece-support-primary-and-sec ondary-school-teachers-put-place-during-pandemic_en

Hine, S., \& Wagner, E. (2021). Progress Under Threat. Save the Children.

Kollender, E., \& Nimer, M. (2020).Long-term exclusionary effects of covid-19 for refugee children in the German and Turkish education systems: a comparative perspective. IPCmercator policy brief, Sabanki University.

König, J., Jäger-Biela, D., \& Glutsch, N. (2020). Adapting to online teaching during COVID-19 school closure: teacher education and teacher competence effects among early career teachers in Germany. European Journal of Teacher Education, 43(4), 608-622. https://doi.org/10.1080/02619768.2020.1809650

Maaoui, A., Tsagari, D., \& Dammak, H. (2021). Teachers' Assessment Literacy and adjustment to the New Normal under COVID-19: Challenges and Prospects. 42nd Language Testing Research Colloquium (LTRC) June 14-17, 2021 (Theme: Assessment in Multilingual Contexts: Models, Practices, Policies \& Challenges). https://www.iltaonline.com/page/LTRC2021

Manoli, P., Mouti, A., \&Kantzou, V. (2021). Children with a Refugee and Migrant 
Background in the Greek Formal Education: A Study of Language Support Classes. Multilingual Academic Journal of Education and Social Sciences, 9(1), 115.http://dx.doi.org/10.46886/MAJESS/v9-i1/7294

OECD. (2020). What is the impact of the COVID-19 pandemic on immigrants and their children? OECD Policy Responses to Coronavirus (COVID-19). https:/www.oecd.org/coronavirus/policy-responses/what-is-the-impact-of-the-covid-19-pand emic-on-immigrants-and-their-children-e 7cbb7de/

Refugee Support Aegean. (2021). Excluded and Segregated. The vanishing education of refugee children in Greece. https://rsaegean.org/en/excluded-and-segregated-the-vanishing-education-of-refugee-children -in-greece/

Save the children. (2020). Meeting our promises to educate refugees during COVID-19 https://www.savethechildren.net/blog/meeting-our-promises-educate-refugees-during-covid-1 9

Simopoulos, G., \&Magos, K. (2021). Approaching the education of young refugees. Teachers' perceptions and students' voices .In Chatzidaki, A. \& Tsokalidou, R. (Eds.), Challenges and Initiatives in Refugee Education: the case of Greece.(pp37-57), Cambridge Scholars Publishing.

Stergiou, L., \& Simopoulos, G. (2019). Meta to container. Diapolitismiki matia stin ekpedefsi prosfigon [After the container. An intercultural view of refugee education]. Gutenberg.

Tsagari, D., Liontou, T., \& Giannikas C. N. (2021). Language Educators Working Online during the COVID-19 Pandemic: Learning, Teaching \& Assessment Practices in the Limelight. Paper presented in 'Safeguarding the Future of Multilingual Assessment in the Covid world' ALTE Conference, 28-30 April, 2021 (digital conference).

UNESCO. (2020a). Education in the time of COVID-19, Report ECLAC-UNESCO https://repositorio.cepal.org/bitstream/handle/11362/45905/1/S2000509_en.pdf

UNESCO. (2020b). Global monitoring of school closures caused by COVID-19.https://en.unesco.org/covid19/educationresponse

UNHCR. (2020). Coming together for Refugee Education.Education Report, 2020.https://www.unhcr.org/5f4f9a2b4.

UNICEF (2019). Refugee and migrant children in Greece.https://www.unicef.org/eca/sites/unicef.org.eca/files/201902/Refugee\%20and\%20mig rant\%20children\%20in\%20Greece\%2031\%20Jan\%202019.pdf

UNICEF. (2020). Refugee and migrant children in Greece as of 30 April 2020.https://www.unicef.org/eca/media/12246/file

UNICEF. (2016). Connecting Refugees. How internet and mobile connectivity can improve refugee well-being and transform humanitarian action.https://www.unhcr.org/5770d43c4.pdf 
Young, A. (2014).Unpacking teachers' language ideologies: attitudes, beliefs, and practiced language policies in schools in Alsace, France.Language Awareness,23(1-2),157-171.https://doi.org/10.1080/09658416.2013.863902

Zambeta, E., Askouni, N., Androusou, A., Leontsini, M., Papadakou, Y., \& Lagopoulou, V. (2019). Refugees in the Greek educational context. In E. Zambeta et al., (Eds.), Democratic school governance for inclusion:a whole community approach. Council of Europe. https://rm.coe.int/publication-democratic-school-governance-for-inclusionweb/ 168094e6e8 